Louisiana State University

LSU Digital Commons

$5-1-2015$

\title{
Morphological variation and different branch modularity across contrasting flow conditions in dominant Pocillopora reef-building corals
}

\author{
David A. Paz-García \\ Instituto Politécnico Nacional \\ Alejandro Aldana-Moreno \\ Instituto Politécnico Nacional \\ Rafael A. Cabral-Tena \\ Instituto Politécnico Nacional \\ Francisco J. García-De-León \\ Instituto Politécnico Nacional \\ Michael E. Hellberg \\ Louisiana State University
}

See next page for additional authors

Follow this and additional works at: https://digitalcommons.Isu.edu/biosci_pubs

\section{Recommended Citation}

Paz-García, D., Aldana-Moreno, A., Cabral-Tena, R., García-De-León, F., Hellberg, M., \& Balart, E. (2015). Morphological variation and different branch modularity across contrasting flow conditions in dominant Pocillopora reef-building corals. Oecologia, 178 (1), 207-218. https://doi.org/10.1007/s00442-014-3199-9

This Article is brought to you for free and open access by the Department of Biological Sciences at LSU Digital Commons. It has been accepted for inclusion in Faculty Publications by an authorized administrator of LSU Digital Commons. For more information, please contact ir@lsu.edu. 


\section{Authors}

David A. Paz-García, Alejandro Aldana-Moreno, Rafael A. Cabral-Tena, Francisco J. García-De-León, Michael E. Hellberg, and Eduardo F. Balart 


\title{
Morphological variation and different branch modularity across contrasting flow conditions in dominant Pocillopora reef-building corals
}

\author{
David A. Paz-García • Alejandro Aldana-Moreno • \\ Rafael A. Cabral-Tena · Francisco J. García-De-León • \\ Michael E. Hellberg · Eduardo F. Balart
}

Received: 19 April 2014 / Accepted: 12 December 2014 / Published online: 4 January 2015

(C) Springer-Verlag Berlin Heidelberg 2015

\begin{abstract}
Pocillopora corals, the dominant reef-builders in the Eastern Tropical Pacific, exhibit a high level of phenotypic plasticity, making the interpretation of morphological variation and the identification of species challenging. To test the hypothesis that different coral morphospecies represent phenotypes that develop in different flow conditions, we compared branch characters in three Pocillopora morphospecies (P. damicornis, P. verrucosa, and P. meandrina) from two communities in the Gulf of California exposed to contrasting flow conditions. Morphological variation and branch modularity (i.e., the tendency of different sets of branch traits to vary in a coordinated way) were assessed in colonies classified as Pocillopora type 1 according to two mitochondrial regions. Our results can be summarized as follows. (1) Pocillopora type 1 morphospecies
\end{abstract}

Communicated by Andrew Baker.

Electronic supplementary material The online version of this article (doi:10.1007/s00442-014-3199-9) contains supplementary material, which is available to authorized users.

D. A. Paz-García · A. Aldana-Moreno · R. A. Cabral-Tena •

E. F. Balart $(\bowtie)$

Laboratorio de Necton y Ecología de Arrecifes, Centro de Investigaciones Biológicas del Noroeste, S.C. (CIBNOR), Instituto Politécnico Nacional 195, Colonia Playa Palo de Santa Rita Sur, 23096 La Paz, Baja California Sur, Mexico e-mail: ebalart04@cibnor.mx

\section{A. Paz-García · F. J. García-De-León}

Laboratorio de Genética para la Conservación, Centro de Investigaciones Biológicas del Noroeste S.C. (CIBNOR), Instituto Politécnico Nacional 195, La Paz 23096, Baja California Sur, Mexico

M. E. Hellberg

Department of Biological Sciences, Louisiana State University, Baton Rouge, LA 70803, USA corresponded to a pattern of morphological variation in the Gulf of California. Overall, $P$. damicornis had the thinnest branches and its colonies the highest branch density, followed by $P$. verrucosa, and then by $P$. meandrina, which had the thickest branches and its colonies the lowest branch density. (2) The differentiation among morphospecies was promoted by different levels of modularity of traits. P. verrucosa had the highest coordination of traits, followed by $P$. damicornis, and P. meandrina. (3) The variation and modularity of branch traits were related to water flow condition. Morphology under the high-flow condition was more similar among morphospecies than under the low-flow condition and seemed to be related to mechanisms for coping with these conditions. Our results provide the first evidence that in scleractinian corals different levels of modularity can be promoted by different environmental conditions.

Keywords Phenotypic modularity · Morphometrics . Pocillopora morphospecies - Phenotypic plasticity . Easter Tropical Pacific · Mitochondrial lineage

\section{Introduction}

Organisms with broad distributions are often exposed to environmental heterogeneity across their geographical range. Environmental heterogeneity can favor different phenotypes between sites and morphological variation along environmental gradients (Veron 1995; Todd 2008; Fusco and Minelli 2010). This difference of expression response is known as phenotypic plasticity and can be, or not, due to an underlying genetic program of the organism (Pigliucci et al. 2006; Zhang et al. 2013). Phenotypic plasticity can contribute to an individual's ability to cope with such environmental variation, as well as with changes 
that occur in one place over an organism's lifetime (Fusco and Minelli 2010; Pfennig et al. 2010). Understanding phenotypic plasticity is crucial to the correct identification of species, accurate estimates of diversity, the application of appropriate efforts of conservation and management, as well as for providing information about mechanisms responsible for morphological variation and its evolutionary potential.

Tropical marine reefs are physically built by sessile organisms (corals, sponges, gorgonians, and algae) that often show a high degree of morphological plasticity. Traditionally, skeletal morphology has been used as the main character for the identification of coral species (Veron and Pichon 1976; Glynn 1999; Veron 2000). However, modular organisms such as corals are composed of repetitive units that exhibit high levels of phenotypic plasticity at each module (Kaandorp 1999; Shaish et al. 2007; Todd 2008; Chindapol et al. 2013). Three units of morphological organization or modules can be distinguished in branching corals: features of (1) individual polyps, (2) individual branches, and (3) the whole colony (Ryaland and Warner 1986; Shaish et al. 2007). Most studies of morphological variation in corals focus on individual branches (Nakamura and Yamasaki 2006; Shaish et al. 2007; Kaniewska et al. 2008; Einbinder et al. 2009), however the coordination of different traits (or lack thereof) can have large effects on the morphological variation, as seen in octocorals (Sánchez and Lasker 2003; Sánchez et al. 2007). This coordination, or integration, of morphological traits implies a strong relationship among the traits that is conditional and mutually informative about patterns of variability and not merely a correlate (Magwene 2001). Modularity refers to the tendency of different sets of branch traits to vary in a coordinated way (Klingenberg 2008, 2014). Thus, characteristics of corals are consistent with the modular concept of phenotypic plasticity seen in plants (de Kroon et al. 2005) in that whole-organism plasticity is the sum of all modular responses triggered by environmental conditions, plus all interaction effects among modules due to the coordination of traits. However, little is known about the effects of modularity in the morphology of scleractinian corals in natural populations.

Differences in skeletal morphology of corals can also be attributed to the disruption of gene flow between populations (Carlon and Budd 2002; Prada et al. 2008). Thus, plastic responses to environmental variation and genetic divergence may occur simultaneously to mold colonial morphology (Mass and Genin 2008; Prada et al. 2008; Todd 2008), making the interpretation of morphological variation and identification of species challenging.

Pocillopora corals illustrate just how challenging the interpretation of morphological variation and species delimitation can be. Members of this genus are widely distributed, ranging from the Red Sea, across the Indian and Pacific Oceans to the Eastern Tropical Pacific (Glynn and Ault 2000; Veron 2000). In the Eastern Tropical Pacific, these corals are found in shallow waters (depth $1-8 \mathrm{~m})$ and are the most important reef-builders in this environment-yet they show a high variation in colony morphology (Glynn and Ault 2000). The identification of species belonging to this genus has been based mainly on the skeletal morphology of the colony, shape and size of the branches and verrucae, and corallite features (Veron and Pichon 1976; Glynn 1999; Veron 2000, 2002). However, studies that included transplants (Nakamura and Yamasaki 2006; Mass and Genin 2008) and growth simulations (Kaandorp 1999; Chindapol et al. 2013) have shown that Pocillopora corals have the capacity to produce different morphologies in response to water flow. In particular, branches of Pocillopora species are thick and compact in habitats exposed to high-flow velocities and thinner and wider under low-flow velocities (Kaandorp 1999; Nakamura and Yamasaki 2006). One possible explanation of these different trait morphologies is that the modifications may be morphological responses of the coral to decrease drag and prevent breakage at high-flow velocities. Under low-flow conditions, thin but wide branches induce turbulence, thereby enhancing the mass transport of nutrients (Chamberlain and Graus 1975; Kaandorp 1999; Einbinder et al. 2009; Filatov et al. 2010). Water flow is not only a critical factor in determining the mechanical aspects of colonial morphology, but it also influences the ability of polyps to capture particles (Sebens et al. 1998) and exchange gas (Sebens et al. 2003; Finelli et al. 2007), and it affects uptake rates (Falter et al. 2004), which in turn affect respiration, photosynthesis, and growth (Finelli et al. 2007; Mass et al. 2010; Schutter et al. 2011) and might also determine susceptibility to bleaching (Nakamura and Yamasaki 2005). Thus, water flow is one of the most important environmental factors influencing the morphology of Pocillopora corals throughout the Eastern Tropical Pacific.

Pocillopora species have been delimited morphologically using numerical taxonomy in Hawaii (Powers 1970; Powers and Rohlf 1972) and Colombia (Cantera et al. 1989), and by morphometric analysis in the Galapagos (Budd 1990). Based on their results, these authors were able to distinguish $P$. damicornis, $P$. capitata, and a group composed of P. elegans-P. eydouxi in the Eastern Tropical Pacific (Cantera et al. 1989; Budd 1990); in Hawaii, $P$. damicornis, $P$. meandrina, and P. lingulata were morphologically differentiated (Powers 1970; Powers and Rohlf 1972). Taxonomic studies have likewise described morphological variation in both recognized species (Veron and Pichon 1976; Veron 2000; Ketchum and Reyes-Bonilla 2001) and novel species (Glynn 1999; Veron 2002), although the authors expressed some uncertainty about 
whether some members of the Pocillopora were synonymous (Reyes-Bonilla 1992; Glynn and Ault 2000).

Genetic studies have reached contrasting results, sparking debate over the validity of Pocillopora morphospecies. Eco-morphs (morphological variants of one morphospecies induced by environmental gradients; Veron and Pichon 1976) of $P$. damicornis have been separated into five distinct genetic lineages in Eastern Australia and two in East Africa (Souter 2010; Schmidt-Roach et al. 2013). Other studies demonstrated congruence between some genetic lineages and morphological data, such as colonial morphology (Flot et al. 2008) and corallite features (Marti-Puig et al. 2014) in Hawaii, but no association between genetic lineage and morphology in the Western Indian Ocean (Pinzón et al. 2013).

In the Eastern Tropical Pacific, three genetic lineages (designated Pocillopora type 1, 2, and 3, respectively) have been distinguished among five Pocillopora morphospecies (P. damicornis, P. verrucosa, $P$. meandrina, $P$. capitata, and $P$. eydouxi) using mitochondrial sequences, microsatellite data, and internal transcribed spacer 2 (ITS2) sequences (Pinzón and LaJeunesse 2011). The most common host group, Pocillopora type 1, displays an association with two Symbiodinium types (C1b-c and D1; Pettay et al. 2011, McGinley et al. 2012), shows high levels of morphological variability, and may include all Pocillopora morphospecies in the Gulf of California (Pinzón and LaJeunesse 2011). Thus, Pocillopora morphospecies may represent plastic responses to environmental conditions that vary over the Eastern Tropical Pacific.

The aims of our study were to test whether three Pocillopora type 1 morphospecies (P. damicornis, P. verrucosa, and $P$. meandrina) correspond to a pattern of morphological variation between different water-flow conditions in two coral communities in the Gulf of California and to determine whether the morphological differentiation among morphospecies is related to the tendency of different sets of branch traits to vary in a coordinated way (i.e., branch modularity).

\section{Materials and methods}

Study sites and water flow

Two coral communities located the southwestern part of the Gulf of California (Fig. 1) were chosen for study because they are exposed to different flow conditions. The coral community at Isla Gaviotas $\left(24^{\circ} 17.187^{\prime} \mathrm{N}, 110^{\circ} 20.382^{\prime} \mathrm{W}\right)$ is exposed to slow currents. The structure of the main reef, composed of Pocillopora, Porites, and Pavona corals, is heterogeneous, with patches of sand as substrate. In contrast, the coral community at Punta Galeras $\left(24^{\circ} 21.276^{\prime} \mathrm{N}\right.$,

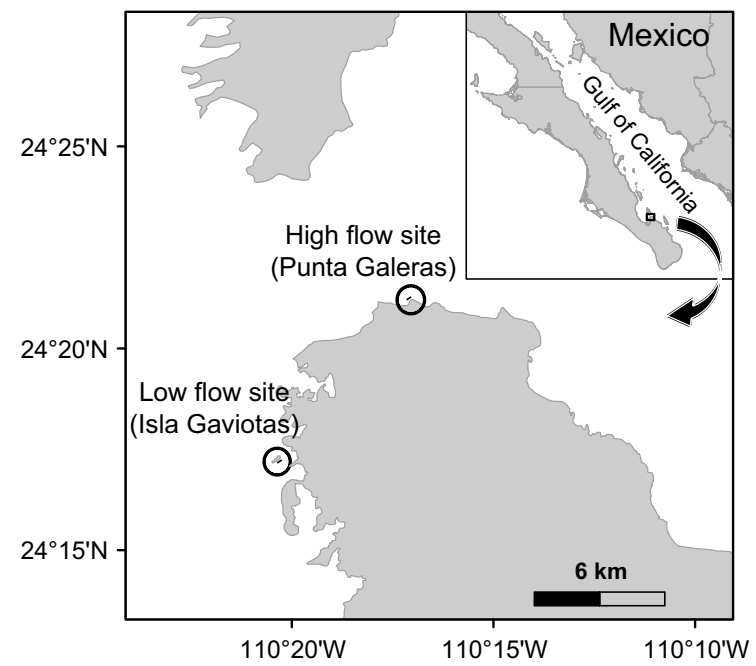

Pocillopora type 1 morphospecies

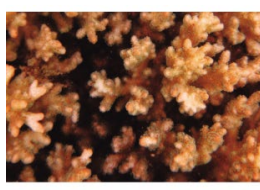

P. damicornis

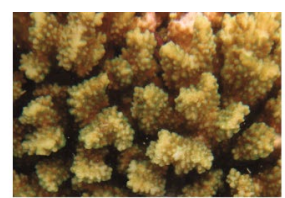

P. verrucosa

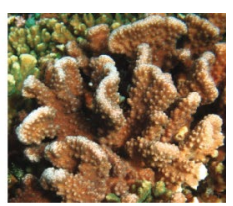

P. meandrina
Fig. 1 Location of low-flow (Isla Gaviotas) and high-flow (Punta Galeras) sites and the Pocillopora type 1 morphospecies analyzed in the southwestern part of the Gulf of California

$110^{\circ} 17.100^{\prime} \mathrm{W}$ ) is exposed to strong wave action. The structure of main reef here is more homogeneous and is rarely interrupted by sand channels (Paz-García and ReyesBonilla 2006; Pinzón et al. 2012).

Two methods were used to estimate the differences in water flow between sites: rate of dissolution of gypsum and rate of dye release. The rate of dissolution of gypsum provides an integrated measure of water flow, and even though it is affected by currents, wave orbital motion, and turbulence, it is a reasonable proxy for differences in mass transfer between sites (Muus 1968; Porter et al. 2000). Gypsum molds were made by mixing $100 \mathrm{~g}$ gypsum with $200 \mathrm{ml}$ water, pouring the slurry into a conical frustum mold, and air-drying the mold until a constant weight was reached. The molds were then glued to acrylic plates with silicon and weighed; each clod card weighed $173 \mathrm{~g}$ [standard error $(\mathrm{SE}) \pm 3.5 \mathrm{~g}]$. Nine molds were deployed at each site on the same day and retrieved after five days during the winter (February 2013). Weight loss per day for each block was calculated and after log-transformation, mean values were compared between sites using the Student's $t$ test. In the second approach, water flow was estimated using dye release (Chamberlain and Graus 1975) along a parallel coast transect of $45 \mathrm{~m}$. In total, $50-100 \mathrm{ml}$ of alizarin red dye $\left(0.8 \mathrm{mg} \mathrm{mL}^{-1}\right)$ was released from a plastic bottle at 
Table 1 List of the Pocillopora morphospecies examined in this study and mitochondrial genetic identity

\begin{tabular}{|c|c|c|c|c|}
\hline Pocillopora morphospecies & $N$ & Pocillopora ORF genetic identity ${ }^{\mathrm{a}}$ & Pocillopora CR genetic identity ${ }^{\mathrm{a}}$ & References \\
\hline P. damicornis & 30 & $\begin{array}{l}\text { Pocillopora type } \\
\qquad 1(n=4, \mathrm{KF} 985974, \mathrm{KF} 985977)\end{array}$ & $\begin{array}{l}\text { Pocillopora sp. A } \\
\quad(n=5, \text { KF985967, KF985970) }\end{array}$ & This study \\
\hline P. verrucosa & 60 & $\begin{array}{l}\text { Pocillopora type } \\
\qquad 1(n=6, \mathrm{KF} 985975, \mathrm{KF} 985978)\end{array}$ & $\begin{array}{l}\text { Pocillopora sp. A } \\
\quad(n=6, \mathrm{KF} 985968, \mathrm{KF} 985971)\end{array}$ & This study \\
\hline P. meandrina & 30 & $\begin{array}{l}\text { Pocillopora type } \\
\qquad 1(n=4, \mathrm{KF} 985976, \mathrm{KF} 985979)\end{array}$ & $\begin{array}{l}\text { Pocillopora sp. A ( } n=10, \text { KF985969, } \\
\text { KF985972) }\end{array}$ & This study \\
\hline Pocillopora & & meandrina (EU374245) & meandrina $(\mathrm{EU} 374279)$ & Flot et al. (2008) \\
\hline Pocillopora & & eydouxi (EU374254) & eydouxi (EF526303) & Flot et al. (2008) \\
\hline Pocillopora & & Sp. A (FR729326) & Sp. A (FR729416) & Flot et al. (2010) \\
\hline Pocillopora & & Type 1 (HQ378758) & - & Pinzón and LaJeunesse (2011) \\
\hline Pocillopora & & meandrina (JX985610) & meandrina (JX625104) & Schmidt-Roach et al. (2013) \\
\hline Pocillopora & & Clade IIb (KF583934) & - & Marti-Puig et al. (2014) \\
\hline
\end{tabular}

$N$, Number of samples used in morphometric analysis

a The Pocillopora open reading frame (ORF) and control region (CR) identity, with the GenBank accession number in parenthesis $(n$, number of colonies used for determining genetic identity)

1-m intervals along the entire transect. Dye measurements were taken in summer (June 2011) and winter (February 2013) during periods of similar tidal cycles. A total of 180 digital videos at 30 frames per second were recorded (90 videos per site). These videos were analyzed using ImageJ 1.34 software (http://rsb.info.nih.gov/ij/) and MtrackJ software (Meijering et al. 2012) to estimate the speed of water flow at a height of $5-10 \mathrm{~cm}$ above the coral colonies (Chamberlain and Graus 1975). The distances recorded in the videos were calibrated using a grid of known dimensions. Elapsed times were measured using the frame rate of the camera. After log-transformation, mean water flow between sites was compared using a two-factor (site $\times$ season) analysis of variance (ANOVA). Post-hoc Tukey tests were used to evaluate significant pairwise differences after ANOVA.

\section{Collection and identification of morphospecies}

We collected 595 fragments from 119 colonies of Pocillopora damicornis $(n=30), P$. verrucosa $(n=60)$, and $P$. meandrina $(n=30)$ morphospecies between March and August 2011 (Fig. 1). Five fragments (approx. $5 \mathrm{~cm}$ long from the tip) were collected from each colony for characterizing morphological variation. Samples were taken at random from different areas of each colony. The fragments were cleaned with $10 \%$ sodium hypochlorite, rinsed in freshwater, and air-dried at room temperature. One small fragment (length $1-3 \mathrm{~cm}$ ) was collected from the center of each colony and preserved in absolute ethanol for molecular analysis. Each specimen was identified to species level according to taxonomic descriptions based on skeleton morphology (Veron and Pichon 1976; Veron 2000;
Ketchum and Reyes-Bonilla 2001). The identification of species based on the underwater pictures was confirmed by taxonomic experts (see "Acknowledgments").

Genetic lineage identity

Genomic DNA was extracted using the protocol of LaJeunesse et al. (2003) and the specifications reported by Pinzón and LaJeunesse (2011). Previous studies using the mitochondrial open reading frame (ORF) indicated that all Pocillopora corals present at Isla Gaviotas and Punta Galeras belong to the Pocillopora type 1 genetic lineage (Pinzón and LaJeunesse 2011; Pinzón et al. 2012). To verify the genetic lineage, we selected 35 colonies representing the three morphospecies (Fig. 1) and amplified the mitochondrial ORF and control region (CR) based on previously published conserved regions from the coral host (Flot et al. 2008, 2010). We developed a new primer using Primer3Web (http://primer3.ut.ee; Untergasser et al. 2012) which amplified a 913-bp fragment: FNC6 (5'-TGG TTG ATG AAT AAG ACA GTT C-3') and RNC6 (5'-CAC CCA TCG AGT TCA ATA A-3'). PCR products were purified and sequenced at a contract research institute (Genewiz, South Plainfield, NJ), and the sequences were edited with Chromas Pro 1.49 beta (Technelysium, Brisbane, Australia). The sequences of the mitochondrial (ORF and CR) morphospecies (Table 1) and those of Pocillopora genetic lineages from previous studies (Flot et al. 2010; Pinzón and LaJeunesse 2011; Schmidt-Roach et al. 2013; Marti-Puig et al. 2014), available on the NCBI database GenBank (Table 1), were aligned and compared with Mega 5 software (Tamura et al. 2011) using the Clustal W application (Thompson et al. 1994). 
Morphometrics

\section{Data acquisition}

To characterize variation in morphology, we focused on five branch traits [Table 2; Electronic Supplementary Material (ESM) Fig. S1] that have been used in previous studies to identify morphospecies, water flow characteristics, and hydro-mechanical adaptations in the family Pocilloporidae (Chamberlain and Graus 1975; Shaish et al. 2007; Stefani et al. 2008; Einbinder et al. 2009). Morphological traits were measured from the collected fragments and from photographs (see Table 2). Measurements were performed with a dial caliper $( \pm 0.1 \mathrm{~mm})$, while ImageJ 1.34 software was used on the photographs. Images were calibrated with a grid of known dimensions.

\section{Patterns of morphological variation}

The mean and SE of the traits were calculated for each morphospecies after first calculating mean values for each colony among the five branch replicates. Data were logtransformed to meet the assumptions of normality (the Kolmogorov-Smirnov test) and homogeneity of variances (Levene test). Two-way ANOVA was used to identify differences in morphological variation attributable to flow conditions (low-flow rate sites vs. high-flow rate sites) and morphospecies identity. A post hoc comparison of means was tested using Tukey's HSD for unequal number of samples when a significant effect was found. The Bonferroni correction was applied to multiple comparisons. Morphological patterns in individual traits was verified according to statistical differences found in ANOVA for individual traits among morphospecies and by Student's $t$ test (differences of traits between sites in each morphospecies; see ESM).

To compare the pattern of variation and test whether morphological differences in Pocillopora type 1 morphospecies remain within each environmental condition, we performed a canonical discriminant analysis among morphospecies per site ( 3 morphospecies $\times 2$ sites, given a total of 6 groups for the analysis). All statistical analyses were performed with Statistical 7 software (StatSoft, Tulsa, OK).

Phenotypic modularity

Modularity of traits within Pocillopora morphospecies and between flow conditions were addressed using a graphical modeling approach that incorporates tests of conditional independence between traits and independence graphs (Magwene 2001). Third-order partial correlation coefficients (PCC) of log-transformed data were calculated. A

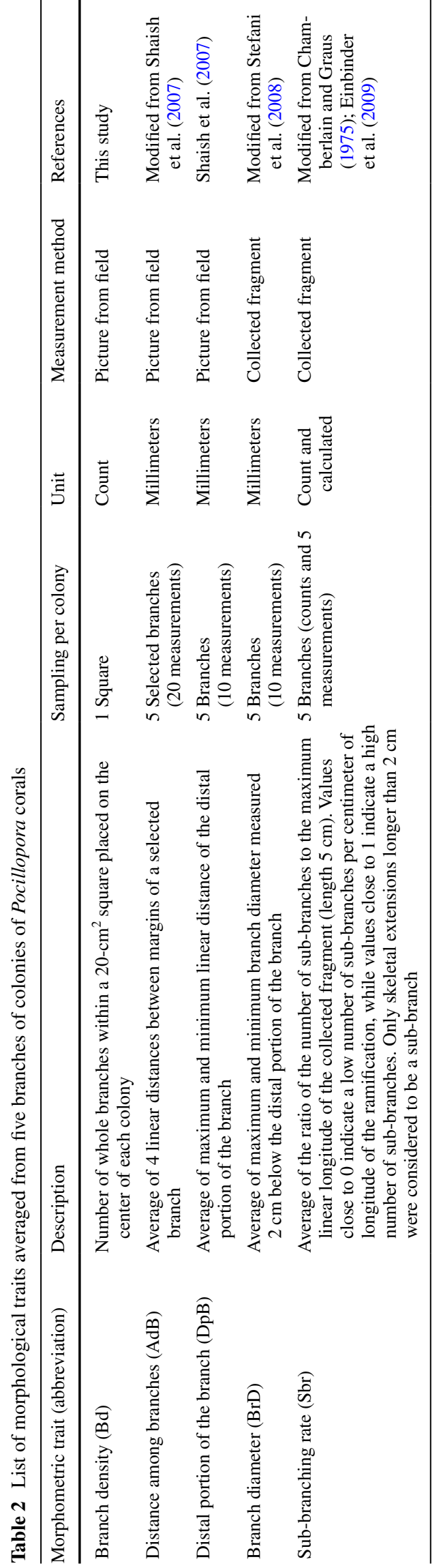


single third-order PCC was estimated for each set of two variables, controlling for the remaining three variables. PCCs were compared statistically for edge exclusion deviance to determine which of the relationships between traits was coordinated in the model. Edge strength was used to detect the differences between strong and weak coordination. The graphic model was constructed for each morphospecies $\times$ flow condition ( 6 different models in total). This graphic model allows the differences in phenotypic modularity of the traits under study to be visualized, where traits are represented by nodes and lines represent extant coordination among traits. High or low modularity will depend on the number of trait connections (lines) in each graphical model.

\section{Results}

\section{Water flow}

The two sites differed in water flow, as evidenced by significant differences in mean weight loss per day in gypsum blocks ( $t_{16}=15.266, p<0.001$, winter season) and by the dye method (ANOVA, MS $=2.20, F_{1,176}=71.19$, $p<0.0001$ ). Gypsum weight loss per day was almost threefold higher at Punta Galeras than at Isla Gaviotas $(28.30 \pm 1.21$ vs. $9.68 \pm 0.603 \mathrm{~g}$, respectively). Water flow measured by the dye method at Punta Galeras was significantly faster than at Isla Gaviotas $(6.84 \pm 0.32$ vs. $4.90 \pm 0.36 \mathrm{~cm} \mathrm{~s}^{-1}$, respectively; average of summer and winter measurements). Water flow differed between seasons (ANOVA, MS $=6.65, F_{1,176}=214.57, p<0.0001$ ), with water flow at both sites higher during the winter (ANOVA, $\left.\mathrm{MS}=1.15, F_{1,176}=37.31, p<0.0001\right)$. The highest difference in water flow between sites occurred in the summer, when water flow was twofold faster at Punta Galeras (5.15 vs. $2.29 \mathrm{~cm} \mathrm{~s}^{-1}$; post hoc Tukey tests $\left.p<0.0001\right)$. Hereafter, Punta Galeras is referred to as the high-flow site and Isla Gaviotas as the low-flow site.

Genetic identity and patterns of morphological variation

A total of 35 sequences were analyzed, all of which were identical over 683- and 908-bp (Table 1) fragments of the mitochondrial ORF and CR, respectively. This result confirmed the genetic identity of the sequences as lineage type 1.

A consistent pattern of morphological differences among morphospecies at each site was revealed by twoway ANOVA (Fig. 2), with a significant difference in the morphological variation of the traits among the three morphospecies (ANOVA, $p<0.001$, all traits) and between the two sites [ANOVA, $p<0.001$ for traits branch density
(Bd), distance among branches (AdB), and sub-branching rate (Sbr)], although the interaction between these factors was not significant (ANOVA site $\times$ morphospecies, $p>0.05$ ). Pocillopora morphospecies remained distinct within (Wilk's $\lambda=0.0898$, approx. $F_{(25,406)}=14.839$, $p<0.0001$; Fig. 3 ) and between sites $(p<0.0001$, all group comparisons), except for colonies of the $P$. meandrina morphospecies at low- versus high-flow sites. This morphological similarity of $P$. meandrina colonies at the two sites resulted in a low correct classification rate at the high-flow site (23.07\%; Fig. 3), while most of the morphospecies groups had a $>68 \%$ correct classification rate (ESM Table S1). Differences in morphological variation were detected between sites since a lower correct classification of morphospecies in the respective group was found at the highflow site $(87.30 \%)$ than at the low-flow site $(92.85 \%)$. These results indicate that colonies of the different morphospecies were more morphologically similar at the highflow site and that, conversely, colonies at the low-flow site were more morphologically differentiated within each morphospecies group.

Branch morphology within sites varied among morphospecies (Figs. 2, 4). Branch thickness values [branch diameter $(\mathrm{BrD})$ and distal portion of branch $(\mathrm{DpB})]$ were lowest in the $P$. damicornis group and highest in the P. meandrina group (Fig. 4). Conversely, $P$. damicornis showed the highest values for $\mathrm{Bd}$ and $\mathrm{Sbr}$, followed by $P$. verrucosa and then P. meandrina (Fig. 4). This pattern of differentiation of morphological traits among the morphospecies was maintained within each site and corroborated by ANOVA and Student's $t$ test (Fig. 2; ESM Tables S2-S4).

Differences in patterns of morphological traits were also found between sites. The morphospecies had a significantly higher $\mathrm{Bd}$ at the high-flow site. At the low-flow site, $P$. damicornis and $P$. verrucosa had a significantly higher distance among branches (Fig. 2). Contrary to other morphospecies, $P$. damicornis had a significantly thicker $\mathrm{DpB}$ at the high-flow site and a higher Sbr at the low-flow site (Fig. 2).

\section{Phenotypic modularity}

The Pocillopora morphospecies exhibited different patterns of morphological modularity under the two flow rate conditions (Fig. 5). Trait coordination was highest in P. verrucosa at both sites, with two coordinated "sub-modules" of traits at the high-flow site. Less coordination between traits was found for $P$. damicornis and $P$. meandrina at the low-flow site. Bd was the most widely coordinated trait, showing a high number of connections in four of the six graphical models (Fig. 5). The connection between Bd with $\mathrm{BrD}$ and $\mathrm{AdB}$ appeared to be stronger at the high-flow site. These results indicate that the branch modularity can be modified by flow conditions. 
Fig. 2 Morphological traits (mean + standard error) among Pocillopora morphospecies at the low-flow $(L F$, orange $)$ and high-flow $(H F$, green $)$ sites. Numbers in parenthesis Number of colonies in each group, **significant $(t$ test, $p<0.01)$ differences. a Branch density $(B D)$, b branch diameter $(B r D)$, c distance among branches $(A d B)$, d sub-branching rate $(S b r)$, e distal portion of the branch $(D p B)$
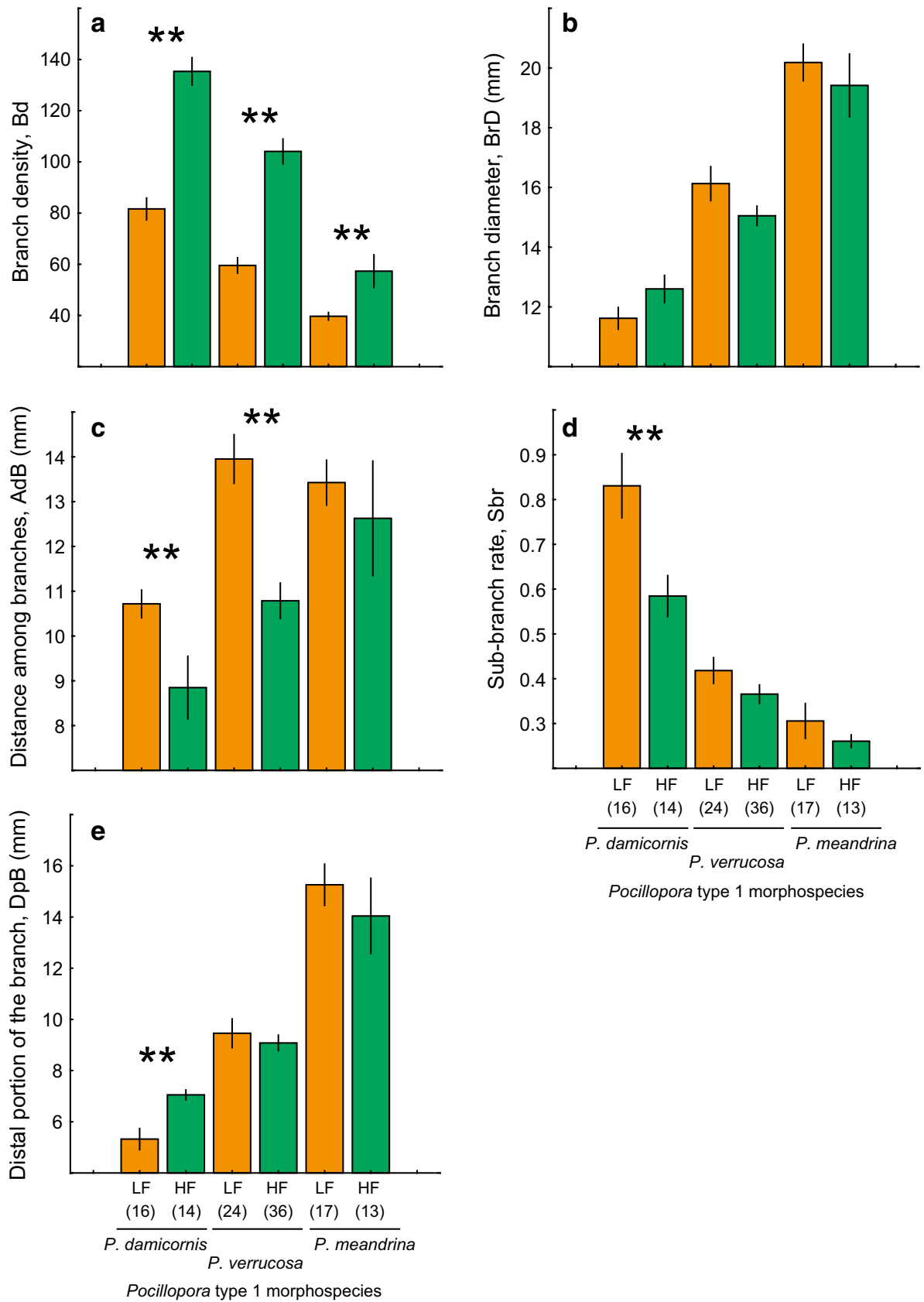

Pocillopora type 1 morphospecies

\section{Discussion}

Genetic identity and patterns of morphological variation

The 35 colonies identified as Pocillopora damicornis, $P$. verrucosa, and $P$. meandrina morphospecies shared identical mitochondrial ORF and CR haplotypes that coincide with "P. meandrina" (Flot et al. 2008; Schmidt-Roach et al. 2013), "P. eydouxi" (Flot et al. 2008), "Pocillopora sp. A" (Flot et al. 2010), and "Clade IIb" (Marti-Puig et al. 2014) throughout the Indo-Pacific. Although this genetic lineage was initially reported by Flot et al. (2010) as "Pocillopora sp. A" in the Eastern Tropical Pacific, we use "Pocillopora type 1" here to match the description of Pocillopora genetic lineages worldwide (Pinzón and LaJeunesse 2011; Forsman et al. 2013; Pinzón et al. 2013; Marti-Puig et al. 2014).

Incongruence between morphology and genetics has been reported in a number of Pocillopora (Flot et al. 2010; Pinzón and LaJeunesse 2011; Forsman et al. 2013) and other scleractinian corals (Eytan et al. 2009; Stat et al. 2012), while mitochondrial lineages have been found to coincide with some eco-morphs of $P$. damicornis and with corallite features (Souter 2010; Schmidt-Roach et al. 2013; Marti-Puig et al. 2014). These results emphasize the need 
Fig. 3 Canonical discriminant analysis of three Pocillopora morphospecies at the low-flow (LF, filled symbols) and high-flow $(H F$, open symbols) sites. Each symbol represents one colony. LF: P. damicornis $(N=16)$, $P$. verrucosa $(N=24), P$. meandrina $(N=17), H F: P$. damicornis $(N=14)$, P. verrucosa $(N=36)$, P. meandrina $(N=13)$. Abbreviations of traits as in Table 1. $c c$ Percentage of correct classification of colonies in each group
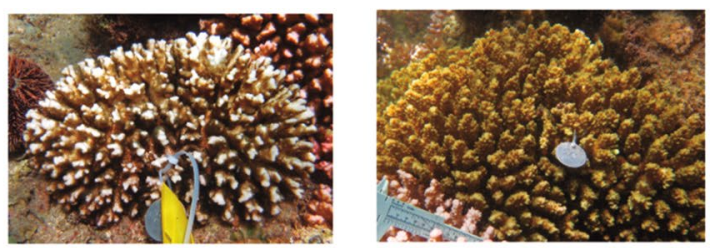

A P. damicornis (LF)

- P. verrucosa (LF)

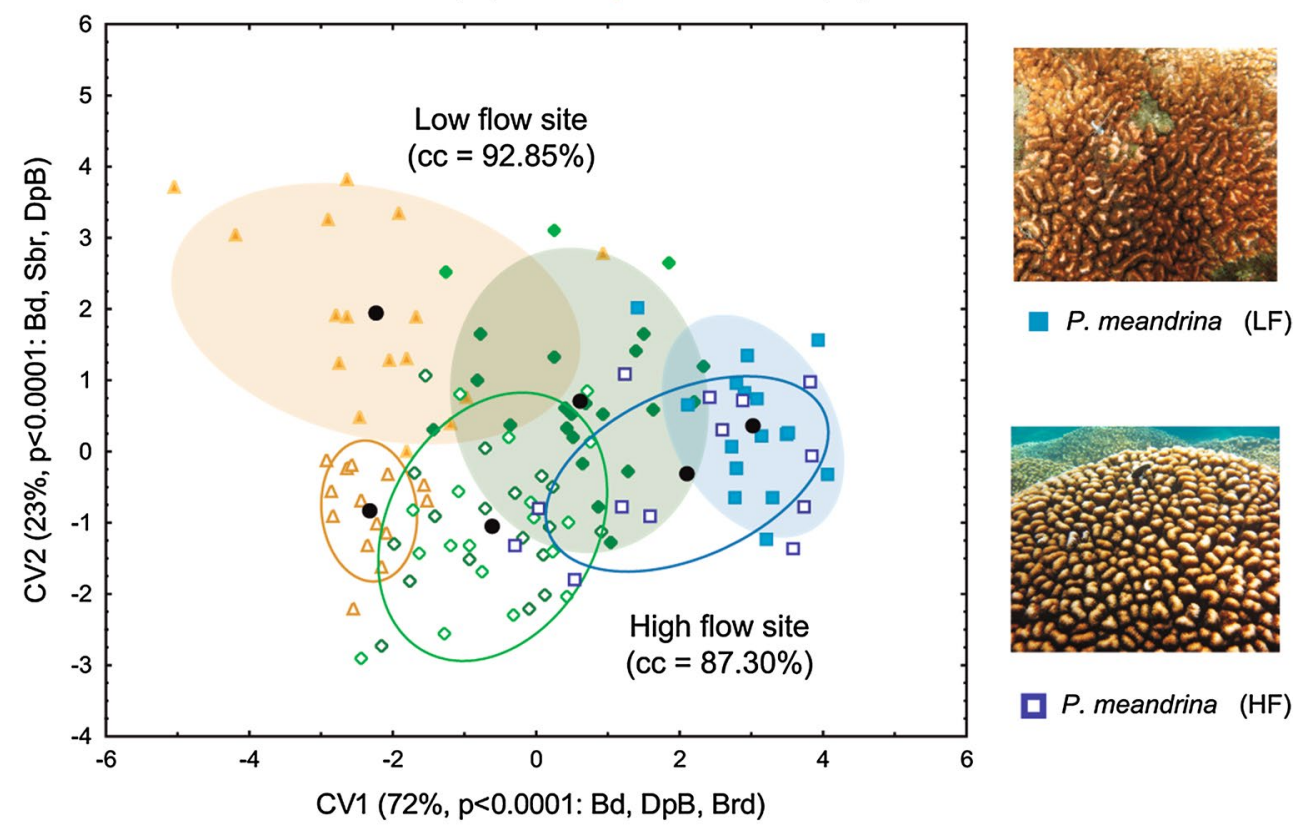

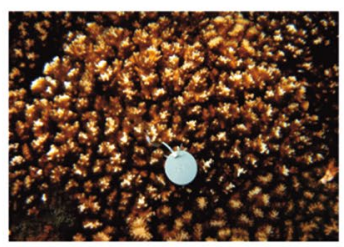

P. damicornis (HF)

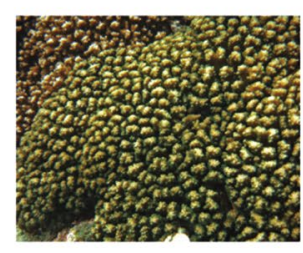

- P. verrucosa (HF)

\section{Pocillopora type 1 morphospecies}

to use molecular markers in combination with morphological analysis to understand morphological variation in genetic lineages in each region.

Despite mitochondrial homogeneity, we found differences among Pocillopora morphospecies that were related to patterns of morphological variation and branch modularity at the two sites (Fig. 3 and following text). A straightforward comparison between our results and those of previous morphological studies (Powers 1970; Powers and Rohlf 1972; Cantera et al. 1989; Budd 1990) cannot be achieved because the genetic identities of morphospecies studied elsewhere are missing and several genetic lineages are present in the Galapagos (type 1 and 3; Pinzón and LaJeunesse 2011) and in Hawaii (type 1, 3 $3^{\mathrm{a}}, 5,6$, and 9; Pinzón et al. 2013; Marti-Puig et al. 2014). Moreover, several genetic lineages show the "P. damicornis", "P. verrucosa", and " $P$. meandrina" phenotypes throughout the Indo-Pacific (Schmidt-Roach et al. 2013; Pinzón et al. 2013; MartiPuig et al. 2014). Future morphological, reproductive, and ecological studies should include genetic identity to ensure comparisons can be made.

We found that Pocillopora morphospecies were more similar at the high-flow site than at the low-flow site and that morphospecies at the high-flow site showed higher morphological overlap and a higher coordination of traits (Figs. 3, 5). Morphological similarity at high flow has been reported for other marine organisms, including macroalgae (Stewart and Carpenter 2003; Roberson and Coyer 2004), corals (Kaandorp 1999; Filatov et al. 2010), and fish (Langerhans et al. 2003). This high morphological similarity does not seem to stem from a lack of genetic differentiation between individuals at the high-flow site, as evidenced an analysis of microsatellite loci by Pinzón et al. (2012) who noted that the high-flow site (Punta Galeras) is composed of many genetically different colonies while the low-flow site (Isla Gaviotas) is dominated by extensive clones. These results are in contrast with those of Aranceta-Garza et al. (2012), who found a higher clonality in $P$. 
Fig. 4 Morphological patterns among Pocillopora morphospecies at different water-flow sites. Direction of arrows indicates an increase of values in the trait. $L F:$ P. damicornis $(N=16)$, $P$. verrucosa $(N=24), P$. meandrina $(N=17), H F$ : $P$. damicornis $(N=14)$, $P$. verrucosa $(N=36), P$. meandrina $(N=13)$
Fig. 5 Modularity among Pocillopora morphospecies at different water flow sites. Traits are represented by nodes, solid lines strong coordination between traits, dashed lines weak coordination. High or low modularity will depend of number of trait connections (lines) in each graphical model. $L F$ : $P$. damicornis $(N=16)$, $P$. verrucosa $(N=24), P$. meandrina $(N=17), H F: P$. damicornis $(N=14), P$. verrucosa $(N=36)$, P. meandrina $(N=13)$. Abbreviation of traits as in Table 2, Fig. 2, and illustrated in ESM Fig. S1

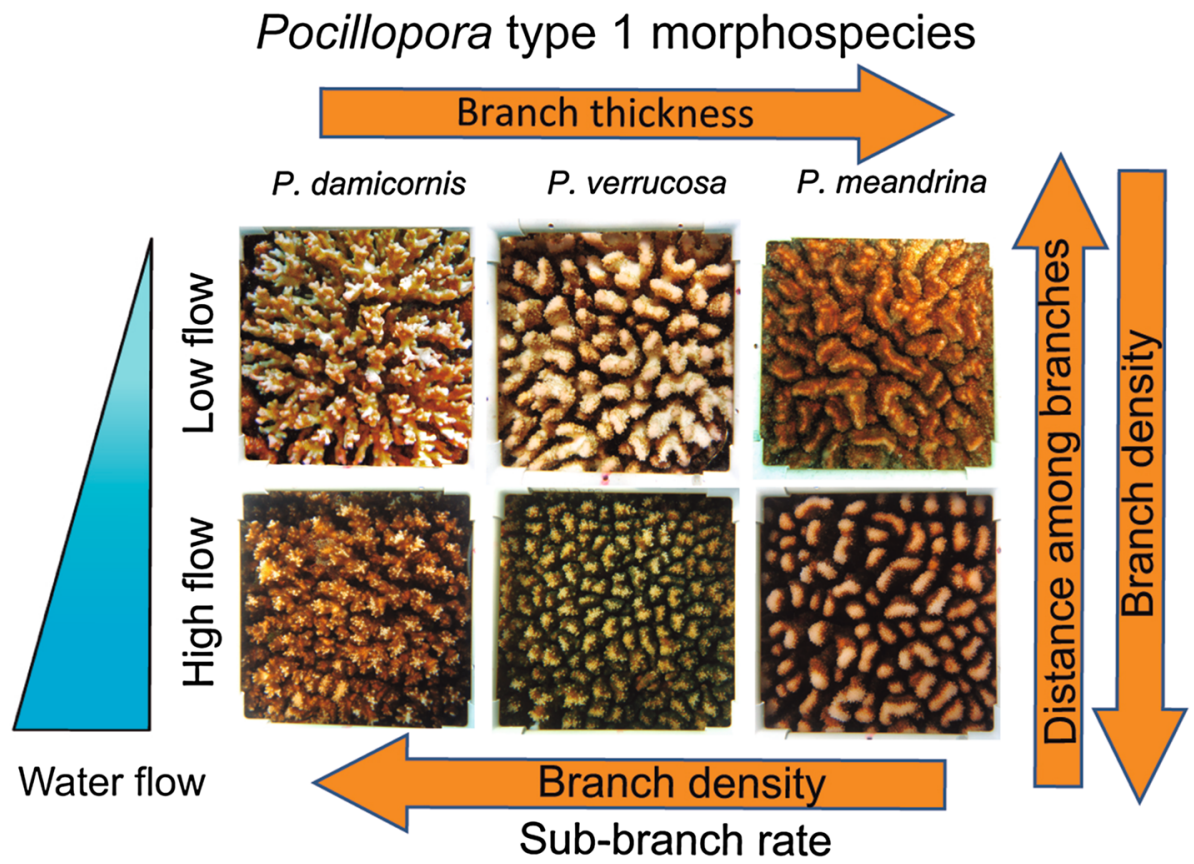

Pocillopora type 1 morphospecies

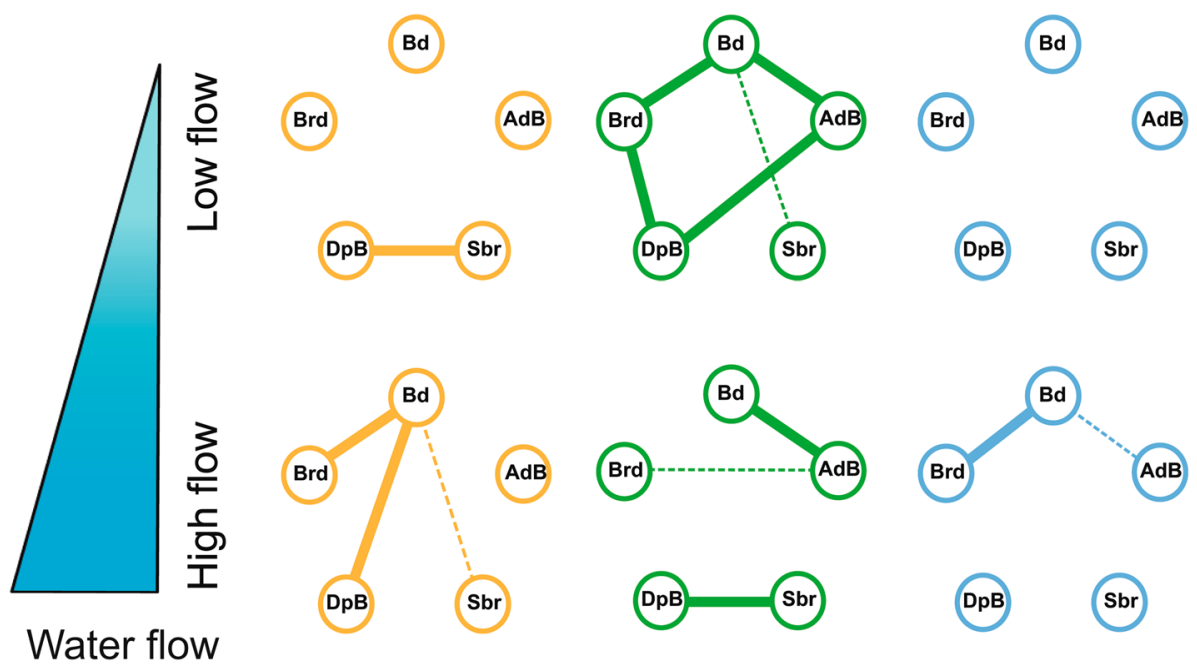

verrucosa in areas of high flow that were also associated with hurricane disturbance. Our results suggest that local environmental conditions trigger morphological responses in Pocillopora type 1 corals and suggest that there may be underlying genetic differences (most likely polygenetic) between the morphospecies even though they share the same mitochondrial DNA.

Colonial morphologies of branching corals respond to the intensity of water flow (Kaandorp 1999; Nakamura and Yamasaki 2006; Kaniewska et al. 2008; Filatov et al. 2010). In our study, differences in flow conditions were associated with morphological patterns in Pocillopora corals and differences in branch modularity (Figs. 3, 5). For example, colonies had a low $\mathrm{Bd}$ and a more open branch structure at low-flow sites and a high Bd and low separation of branches at high-flow sites. Similar patterns of variation in the compactness of colonial morphologies have been described in other branching corals (Acropora, Madracis, Seriatopora, Stylophora, and Pocillopora) (Kaniewska et al. 2008; Kaandorp 1999; Filatov et al. 2010). Differences in Bd and AdB in Pocillopora corals could be a result of adjustments to physiological and mechanical 
requirements. For example, under low-flow conditions, an increasing Bd results in higher respiration and particle capture rates (Sebens et al. 1997; Bruno and Edmunds 1998), while at high-flow sites a more compact colony form could strengthen mechanical resistance.

Although morphological patterns were evident in Bd and the $\mathrm{AdB}$, these traits were not coordinated with the other traits examined in all morphospecies (detected only in 3 of the 6 graphical models; Fig. 5). This indicates that alternative morphological changes can occur under different coordination of traits. Changes in modular plasticity depend largely on the spatial and seasonal match between variation in environmental conditions that affect the development of the organism and the plastic responses in each module (Huber et al. 2004). Thus, depending on environmental conditions, coordinated responses of modules will be favored for fine-tuning the phenotype appropriate to the local habitat (de Kroon et al. 2005). These plastic responses and interactions within and between modules add exponential complexity to each modular level and to the final morphological configuration of the whole colony. Our results provide the first evidence that branch modularity of scleractinian corals can vary and that this variation is promoted by different flow conditions.

The Pocillopora morphospecies studied here showed additional morphological patterns in the branch thickness (BrD) and $\mathrm{DpB}$ traits and Bd (Fig. 3), with the variations ranging from $P$. damicornis, which had the thinnest branches and highest density of branched colonies, to $P$. verrucosa, and then P. meandrina (Fig. 3). Changes in $\mathrm{BrD}$ have been reported in Stylophora and Pocillopora corals exposed to different flow treatments, where thin branches developed under low-flow conditions and thicker branches developed under high-flow conditions (Nakamura and Yamasaki 2006). We expected to find differences in $\mathrm{BrD}$ between sites, but found instead differences in $\mathrm{BrD}$ mainly among morphospecies within sites (related to differences in modularity of these traits) and not within each morphospecies between sites. Only $P$. damicornis showed a significant difference between sites-for DpB (Fig. 2). This integration of traits occurred at the high-flow site and was not coordinated with other traits at the low-flow site (Fig. 5). These results indicate that branch modularity can be modified by flow rates, with high coordination among traits at the high-flow sites, and that morphological differentiation in Pocillopora morphospecies is related to this difference in branch modularity.

Our results suggest that conditions at both sites produced changes in the morphology of coral colonies, even though they maintained their morphospecies identity. Prada et al. (2008) showed that octocorals transplanted to different depths were able to alter their morphology to be more like the native morphotypes, but they still maintained non-overlapping morphologies that were correlated with genetic differences in mitochondrial and nuclear genes. In our study, no mitochondrial differences distinguished the Pocillopora morphospecies. It may be that an underlying genetic program responds to external environmental conditions, subsequently constraining or relaxing the expression (phenotype).

Morphological differentiation in Pocillopora morphospecies was related to a difference in branch modularity (Fig. 5). In octocorals (Sánchez and Lasker 2003; Sánchez et al. 2007) and plants (de Kroon et al. 2005) trait coordination can change across environmental gradients, where differences in the coordination and non-coordination of traits within modules as well as module interactions have been detected depending on local conditions. Studying trait variation and modularity may provide crucial insights into the expression of variable phenotypes having either integrative or autonomous effects on each coral. Morphological variation in Pocillopora morphospecies is related to modifications in the coordination of traits by local responses at the branch modular level.

In summary, our findings show that Pocillopora type 1 morphospecies (P. damicornis, $P$. verrucosa, and P. meandrina) correspond to a pattern of morphological variation in the Gulf of California and that differentiation among morphospecies is promoted by different levels of branch modularity. Additional evidence, such as differences in abundance and spatial distribution among the Pocillopora morphospecies (Paz-García et al. 2012) and changes in branch and colony morphology between morphospecies over the short term (Paz-García et al., unpublished data), support these results. In addition, we found that the variation in branch traits was related to water-flow conditions: morphology was more similar among morphospecies under high-flow conditions than under low-flow conditions and was seemingly related to mechanisms for coping with these conditions.

We suggest that a change in perspective is needed to better understand morphological diversity in scleractinian corals-from that of studying morphological variation as gradual changes of the whole colony (Veron and Pichon 1976) toward studying variation as a product of different responses and interactions at modular levels (de Kroon et al. 2005). This change should improve our understanding of complex colonial organisms. New approaches which combine morphological, genomic, and detailed environmental data are required to determine the underlying genetic factors in phenotype variation and the influence of the environment in the modulation of plasticity in scleractinian corals.

Acknowledgments We thank David Vega, Fernando Aranceta, Pedro González, and Mario Cota of CIBNOR, Saúl González and Salwa El Khattabi of UABCS, Angélica Campos and José Meléndez of CICIMAR for field assistance, and Noemí Bocanegra Castillo of CIBNOR for laboratory assistance. We thank John E. N. Veron, Peter W. Glynn, 
Jorge Cortés, Héctor Reyes Bonilla, and Andrés López Pérez for their corroboration of species. We are grateful to Johanna H. Rosman and Todd C. LaJeunesse for their comments of an earlier version of the manuscript. We also thank the editors and anonymous reviewers for their helpful comments and suggestions. Ira Fogel of CIBNOR provided editorial services. Funding was provided by CONACYT (grant 157993) to EFB and 2011 UNESCO-MAB Young Scientists to DAPG. DAPG, RACT, and AAM are recipients of student fellowships from CONACYT $(160065,212435$, and 236332, respectively).

\section{References}

Aranceta-Garza F, Balart EF, Reyes-Bonilla H, Cruz-Hernández P (2012) Effect of tropical storms on sexual and asexual reproduction in coral Pocillopora verrucosa subpopulations in the Gulf of California. Coral Reefs 31:1157-1167

Bruno JF, Edmunds PJ (1998) Metabolic consequences of phenotypic plasticity in the coral Madracis mirabilis (Duchassaing and Michelotti): the effect of morphology and water flow on aggregate respiration. J Exp Mar Biol Ecol 229:187-195

Budd AF (1990) Long term patterns of morphological variation within and among species of reef-corals and their relationship to sexual reproduction. Syst Bot 15:150-165

Cantera JR, von Prahl H, Escobar JC, Peña E (1989) Sistemática de los corales del género Pocillopora del pacífico colombiano utilizando taxonomía numérica. Rev Biol Trop 37:23-28

Carlon DB, Budd AF (2002) Incipient speciation across a depth gradient in a scleractinian coral? Evolution 56:2227-2242

Chamberlain JA, Graus RR (1975) Water flow and hydromechanical adaptations of branched reef corals. Bull Mar Sci 25:112-125

Chindapol N, Kaandorp Ja, Cronemberger C, Mass T, Genin A (2013) Modelling growth and form of the scleractinian coral Pocillopora verrucosa and the influence of hydrodynamics. PLoS Comput Biol 9:e1002849

De Kroon H, Huber H, Stuefer JF, van Groenendael JM (2005) A modular concept of phenotypic plasticity in plants. New Phytol 166:73-82

Einbinder S, Mass T, Brokovich E, Dubinsky Z, Erez J et al (2009) Changes in morphology and diet of the coral Stylophora pistillata along a depth gradient. Mar Ecol Prog Ser 381:167-174

Eytan RI, Hayes M, Arbour-Reily P, Miller M, Hellberg ME (2009) Nuclear sequences reveal mid-range isolation of an imperiled deep-water coral population. Mol Ecol 18:2375-2389

Falter JL, Atkinson MJ, Merrifield MA (2004) Mass-transfer limitation of nutrient uptake by a wave-dominated reef flat community. Limnol Oceanogr 49:1820-1831

Filatov MV, Kaandorp JA, Postma M, van Liere R, Kruszyński KJ et al (2010) A comparison between coral colonies of the genus Madracis and simulated forms. Proc Biol Sci 277:3555-3561

Finelli C, Helmuth B, Pentcheff N, Wethey D (2007) Intracolony variability in photosynthesis by corals is affected by water flow: role of oxygen flux. Mar Ecol Prog Ser 349:103-110

Flot J-F, Magalon H, Cruaud C, Couloux A, Tillier S (2008) Patterns of genetic structure among Hawaiian corals of the genus Pocillopora yield clusters of individuals that are compatible with morphology. C R Biol 331:239-247

Flot J-F, Couloux A, Tillier S (2010) Haplowebs as a graphical tool for delimiting species: a revival of Doyle's "field for recombination" approach and its application to the coral genus Pocillopora in Clipperton. BMC Evol Biol 10:372

Forsman ZH, Johnston EC, Brooks AJ, Adam TC, Toonen RJ (2013) Genetic Evidence for Regional Isolation of Pocillopora Corals from Moorea. Oceanography 26:153-155. doi:10.5670/ oceanog.2013.58.\#sthash.dSpISpvb.6S9U1VAN.dpuf
Fusco G, Minelli A (2010) Phenotypic plasticity in development and evolution: facts and concepts. Introduction. Philos Trans R Soc Lond B Biol Sci 365:547-556

Glynn PW (1999) Pocillopora inflata, a new species of scleractinian coral (Cnidaria: Anthozoa) from the Tropical Eastern Pacific. Pac Sci 53:168-180

Glynn PW, Ault JS (2000) A biogeographic analysis and review of the far eastern Pacific coral reef region. Coral Reefs 19:1-23

Hellberg ME (2006) No variation and low synonymous substitution rates in coral mtDNA despite high nuclear variation. BMC Evol Biol 6:24

Huber H, Kane NC, Heschel MS, von Wettberg EJ, Banta J et al (2004) Frequency and microenvironmental pattern of selection on plastic shade-avoidance traits in a natural population of Impatiens capensis. Am Nat 163:548-563

Kaandorp JA (1999) Morphological analysis of growth forms of branching marine sessile organisms along environmental gradients. Mar Biol 134:295-306

Kaniewska P, Anthony KRN, Hoegh-Guldberg O (2008) Variation in colony geometry modulates internal light levels in branching corals, Acropora humilis and Stylophora pistillata. Mar Biol 155:649-660

Ketchum JT, Reyes-Bonilla H (2001) Taxonomía y distribución de los corales hermatípicos (Scleractinia) del Archipiélago de Revillagigedo, México. Rev Biol Trop 49:803-848

Klingenberg CP (2008) Morphological integration and developmental modularity. Annu Rev Ecol Evol Syst 39:115-132

Klingenberg CP (2014) Studying morphological integration and modularity at multiple levels: concepts and analysis. Phil Trans R Soc B 369: 20130249.

LaJeunesse TC, Loh WKW, van Woesik R, Hoegh-Guldberg O, Schmidt GW, Fitt WK (2003) Low symbiont diversity in southern Great Barrier Reef corals relative to those of the Caribbean. Limnol Oceanogr 48:2046-2054

Langerhans RB, Layman CA, Langerhans AK, Dewitt TJ (2003) Habitat-associated morphological divergence in two Neotropical fish species. Biol J Linnean Soc 80:689-698

Magwene PM (2001) New tools for studying integration and modularity. Evolution 55:1734-1745

Marti-Puig P, Forsman Z, Haverkort-Yeh R, Knapp I, Maragos J, Toonen R (2014) Extreme phenotypic polymorphism in Pocillopora (Anthozoa: Scleractinia); corallite morphology corresponds to mitochondrial groups, while taxonomy based on colony morphology does not. Bull Mar Sci 90:211-231

Mass T, Genin A (2008) Environmental versus intrinsic determination of colony symmetry in the coral Pocillopora verrucosa. Mar Ecol Prog Ser 369:131-137

Mass T, Genin A, Shavit U, Grinstein M, Tchernov D (2010) Flow enhances photosynthesis in marine benthic autotrophs by increasing the efflux of oxygen from the organism to the water. Proc Natl Acad Sci USA 107:2527-2531

McGinley MP, Aschaffenburg MD, Pettay DT, Smith RT, LaJeunesse TC, Warner ME (2012) Symbiodinium spp. in colonies of eastern Pacific Pocillopora spp. are highly stable despite the prevalence of low-abundance background populations. Mar Ecol Prog Ser 462:1-7

Meijering E, Dzyubachyk O, Smal I (2012) Methods for cell and particle tracking. Methods Enzymol 504:183-200

Muus B (1968) A field method for measuring "exposure" by means of plaster balls: a preliminary account. Sarsia 34:61-68

Nakamura T, Yamasaki H (2005) Requirement of water-flow for sustainable growth of Pocilloporid corals during high temperature periods. Mar Pollut Bull 50:1115-1120

Nakamura T, Yamasaki H (2006) Morphological changes of pocilloporid corals exposed to water flow. Proc 10th Int Coral Reef Symp 875:872-875 
Paz-García DA, Reyes-Bonilla H (2006) Temporal variation in the regeneration rate of artificial lesions in two morphotypes of Porites panamensis. Cienc Mar 32:187-194

Paz-García DA, Balart EF, García-de-Léon FJ (2012) Cold water bleaching of Pocillopora in the Gulf of California. In: Proceedings of the 12th International Coral Reef Symposium, Cairns, Australia, 9-13 July 2012. 9A Coral bleaching and climate change

Pettay DT, Wham DC, Pinzón JH, LaJeunesse TC (2011) Genotypic diversity and spatial-temporal distribution of Symbiodinium clones in an abundant reef coral. Mol Ecol 20:5197-5212

Pfennig DW, Wund MA, Snell-Rood EC, Cruickshank T, Schlichting CD et al (2010) Phenotypic plasticity's impacts on diversification and speciation. Trends Ecol Evol 25:459-467

Pigliucci M, Murren CJ, Schlichting CD (2006) Phenotypic plasticity and evolution by genetic assimilation. J Exp Biol 209:2362-2367

Pinzón JH, LaJeunesse TC (2011) Species delimitation of common reef corals in the genus Pocillopora using nucleotide sequence phylogenies, population genetics and symbiosis ecology. Mol Ecol 20:311-325

Pinzón JH, Reyes-Bonilla H, Baums IB, LaJeunesse TC (2012) Contrasting clonal structure among Pocillopora (Scleractinia) communities at two environmentally distinct sites in the Gulf of California. Coral Reefs 31:765-777

Pinzón JH, Sampayo E, Cox E, Chauka LJ, Chen CA et al (2013) Blind to morphology: genetics identifies several widespread ecologically common species and few endemics among IndoPacific cauliflower corals (Pocillopora, Scleractinia). J Biogeogr 40:1595-1608

Porter ET, Sanford LP, Suttles SE (2000) Gypsum dissolution is not a universal integrator of water motion. Limnol Oceanogr 45:145-158

Powers D (1970) A numerical taxonomic study of Hawaiian reef corals. Pacific Sci 24:180-186

Powers DA, Rohlf FJ (1972) A numerical taxonomic study of Caribbean and Hawaiian reef coral. Syst Zool 21:53-64

Prada C, Schizas NV, Yoshioka PM (2008) Phenotypic plasticity or speciation? A case from a clonal marine organism. BMC Evol Biol 8:47. doi:10.1186/1471-2148-8-47

Reyes-Bonilla H (1992) New records for hermatypic corals (Anthozoa: Scleractinia) in the Gulf of California, Mexico, with an historical and biogeographical discussion. J Nat Hist 26:1163-1175

Roberson L, Coyer J (2004) Variation in blade morphology of the kelp Eisenia arborea: incipient speciation due to local water motion? Mar Ecol Prog Ser 282:115-128

Ryaland JS, Warner GF (1986) Growth and form in modular animals: ideas on the size and arrangement of zooids. Phil Trans R Soc B Biol Sci 313:53-76

Sánchez JA, Lasker HR (2003) Patterns of morphological integration in marine modular organisms: supra-module organization in branching octocoral colonies. Proc Biol Sci 270:2039-2044

Sánchez JA, Aguilar C, Dorado D, Manrique N (2007) Phenotypic plasticity and morphological integration in a marine modular invertebrate. BMC Evol Biol 7:122

Schmidt-Roach S, Lundgren P, Miller KJ, Gerlach G, Noreen AME, Andreakis N (2013) Assessing hidden species diversity in the coral Pocillopora damicornis from Eastern Australia. Coral Reefs 32:161-172

Schutter M, Kranenbarg S, Wijffels RH, Verreth J, Osinga R (2011) Modification of light utilization for skeletal growth by water flow in the scleractinian coral Galaxea fascicularis. Mar Biol 158:769-777
Sebens K, Witting J, Helmuth B (1997) Effects of water flow and branch spacing on particle capture by the reef coral Madracis mirabilis (Duchassaing and Michelotti). J Exp Mar Biol 211:1-28

Sebens KP, Grace SP, Helmuth B, Maney EJ Jr, Miles JS (1998) Water flow and prey capture by three scleractinian corals, Madracis mirabilis, Montastrea cavernosa and Porites porites, in a field enclosure. Mar Biol 131:347-360

Sebens KP, Helmuth B, Carrington E, Agius B (2003) Effects of water flow on growth and energetics of the scleractinian coral Agaricia tenuifolia in Belize. Coral Reefs 22:35-47. doi:10.1007/ s00338-003-0277-6

Shaish L, Abelson A, Rinkevich B (2007) How plastic can phenotypic plasticity be? The branching coral Stylophora pistillata as a model system. PLoS One 2:e644

Shearer TL, Van Oppen MJH, Romano SL, Wörheide G (2002) Slow mitochondrial DNA sequence evolution in the Anthozoa (Cnidaria). Mol Ecol 11:2475-2487

Souter P (2010) Hidden genetic diversity in a key model species of coral. Mar Biol 157:875-885

Stat M, Baker AC, Bourne DG, Correa AMS, Forsman Z, Huggett M, Pochon X, Skillings D, ToonenR, van Oppen MJH, Gates RD (2012) Molecular delineation of species in the coral holobiont. Adv Mar Biol 63:1-65

Stefani F, Benzoni F, Pichon M, Cancelliere C, Galli P (2008) A multidisciplinary approach to the definition of species boundaries in branching species of the coral genus Psammocora (Cnidaria, Scleractinia). Zool Scr 37:1463-6409

Stewart HL, Carpenter RC (2003) The effects of morphology and water flow on photosynthesis of marine macroalgae. Ecology 84:2999-3012

Tamura K, Peterson D, Peterson N, Stecher G, Nei M, Kumar S (2011) MEGA5: molecular evolutionary genetics analysis using maximum likelihood, evolutionary distance, and maximum parsimony methods. Mol Biol Evol 28:2731-2739. doi:10.1093/ molbev/msr121

Thompson JD, Higgins DG, Gibson TJ (1994) CLUSTAL W: improving the sensitivity of progressive multiple sequence alignment through sequence weighting, position-specific gap penalties and weight matrix choice. Nucleic Acids Res 22:4673-4680. doi:10.1093/nar/22.22.4673

Todd PA (2008) Morphological plasticity in scleractinian corals. Biol Rev 83:315-337

Untergasser A, Cutcutache I, Koressaar T, Ye J, Faircloth BC, Remm M, Rozen SG (2012) Primer3-new capabilities and interfaces. Nucleic Acids Res 40:e115

Veron JEN (1995) Corals in space and time: biogeography and evolution of the Scleractinia. Australian Institute of Marine Science, Townsville

Veron JEN (2000) Corals of the world. Australian Institute of Marine Science, Townsville

Veron JEN (2002) New species described in corals of the world. Aust Inst Mar Sci Monogr Ser 11:1-206

Veron JEN, Pichon M (1976) Scleractinia of eastern Australia, part I. Families Thamnasteridae, Astrocoeniidae, Pocilloporidae. Aust Inst Mar Sci, Monogr Ser 1:1-86

Zhang Y-Y, Fischer M, Colot V, Bossdorf O (2013) Epigenetic variation creates potential for evolution of plant phenotypic plasticity. New Phytol 197:314-322 